\title{
PARTICULARIDADES NAS CONTRATAÇÕES DE INOVAÇÃO E DESENVOLVIMENTO TECNOLÓGICO DA ADMINISTRAÇÃO PÚBLICA
}

\author{
Eduardo Biserra Rocha* \\ Juliana Da Silva Ribeiro Gomes Chediek ${ }^{* *}$
}

\section{RESUMO}

O presente trabalho busca analisar os contratos de pesquisa, inovação e desenvolvimento tecnológico da Administração Pública, destacando especificidades em relação aos demais contratos administrativos no contexto da atual doutrina, legislação e jurisprudência. Principalmente no Poder Executivo, é frequente que se almeje desenvolver produtos e/ou serviços cuja a tecnologia ainda não é existente para aquisição e pronta-entrega no mercado. Diante da lacuna, a Administração pode celebrar contratos a fim de viabilizar tais inovações, as quais se dão, principalmente, nas áreas de defesa, tecnologia da informação e petróleo. $\mathrm{O}$ artigo intenta aprofundar o estudo sobre as principais características comuns a estas contratações.

Palavras-chave: contratos da Administração, inovação, pesquisa e desenvolvimento, novas tecnologias, licitações

\section{PARTICULARITIES IN THE CONTRACTING OF INNOVATION AND TECHNOLOGICAL DEVELOPMENT OF PUBLIC ADMINISTRATION}

\begin{abstract}
The present work seeks to analyze Administration's contracts of research, innovation and technological development, highlighting specifications in comparing to other administrative contracts in the context of current doctrine, legislation and jurisprudence. Especially in the Executive Branch, it is often desired to develop products and/or services whose technology are not yet available for acquisition and prompt delivery. Facing the gap, the Administration can contract in order to make feasible such innovations, which happen mainly in the areas of defense, information technology and oil. The article tries to deepen the study on the main characteristics common to these hirings.
\end{abstract}

Keywords: Administration's contracts; innovation; research and development; new technologies; biddings

\section{INTRODUÇÃO}

O presente trabalho busca destacar as particularidades nas contratações administrativas sobre inovação, pesquisa e desenvolvimento de novas tecnologias em relação aos demais contratos da Administração.

Principalmente no âmbito do Poder Executivo, é frequente que o administrador busque adquirir produtos e/ou serviços cuja a tecnologia ainda não é existente para pronta- 
entrega no mercado. Nesses casos - muito recorrentes em matéria de produtos de defesa nas Forças Armadas, no desenvolvimento de equipamentos para exploração geológica e também nas aquisições na área de tecnologia de informação - a Administração deverá utilizar-se das regras gerais de contratações pública, atentando-se para as particularidades da contratação, as quais serão destacadas a seguir.

A guiza de princípio, frise-se que a Constituição Federal de 1988 estabeleceu a regra geral do processo de licitação pública, em seu artigo 37, inciso XXI (BRASIL, 1988), disciplinado pela Lei $n^{\circ}$ 8.666/1993 (BRASIL, 1993), e dada a relevância estratégica das contratações de inovação tecnológica tendo em vista o fomento da indústria nacional bem como as implicações no que tange à geração de receitas e de empregos para o país, a concorrência pode configurar a melhor modalidade licitatória a fim de atingir o desiderato administrativo. De outras vezes, pode ser que emerjam soluções baseadas em exceções ao processo geral de contratação - quais sejam, a contratação direta por inexigibilidade ou por dispensa de licitação (artigos 24 e 25 da Lei 8.666/1993) - tudo a depender do caso concreto.

A experiência da Administração Federal nas contratações em matéria de inovação tecnológica, guiada pelos profícuos pareceres proferidos pelos órgãos consultivos da Consultoria Jurídica da União (órgão consultivo da Advocacia-Geral da União nos estados) quando da análise dos processos administrativos de contratação de pesquisa e desenvolvimento de produtos e serviços, vem demonstrando, na prática, a recorrência de algumas peculiaridades a serem observadas na condução de tais processos e, principalmente, na elaboração das minutas dos contratos de pesquisa e desenvolvimento tecnológico. Se é vasta a experiência prática, por outro lado, é escassa a doutrina acerca do tema, em razão de suas particularidades.

Dentro desse contexto, o presente trabalho objetiva realizar um breve apanhado dos principais pontos a serem destacados nas contratações públicas de produtos e serviços em pesquisa, desenvolvimento e inovação, buscando dar suporte às contratações a serem realizadas pela Administração, bem como contribuir para o incremento do incentivo à inovação e à pesquisa científica e tecnológica e ao desenvolvimento do sistema produtivo nacional e regional, nos moldes previstos nos artigos 218, 219, 219-A e 219-B da Constituição Federal (BRASIL, 1988) ${ }^{1}$.

1 Art. 218. O Estado promoverá e incentivará o desenvolvimento científico, a pesquisa, a capacitação científica e tecnológica e a inovação. $\S 1^{\circ} \mathrm{A}$ pesquisa científica básica e tecnológica receberá tratamento prioritário do Estado, tendo em vista o bem público e o progresso da ciência, tecnologia e inovação. $\S 2^{\circ} \mathrm{A}$ pesquisa tecnológica voltar-se-á preponderantemente para a solução dos problemas brasileiros e para o desenvolvimento do sistema produtivo nacional e regional. $\S 3^{\circ} \mathrm{O}$ Estado apoiará a formação de recursos 


\section{POSSIBILIDADE DE UTILIZAÇÃo DO PROCEDIMENTO AUXILIAR DE PRÉ- QUALIFICAÇÃO.}

Muitas vezes o administrador público, ao procurar no mercado o produto ou serviço que deseja adquirir, não encontra, prontamente, bem apto a cumprir as especificações desejadas em razão das complexidades tecnológicas intrínsecas ao projeto. Isto acontece porque, em matéria de pesquisa e desenvolvimento de bens de alta complexidade tecnológica, busca-se inovar e criar produto/serviço para além do estado atual da técnica, a fim de atingir o escopo buscado pela Administração.

Nesta senda, não é incomum que poucos fornecedores possuam a expertise necessária para realizar o projeto almejado, com todas as suas especificidades tecnológicas. Nesses casos, relacionados a programas de larga complexidade, é possível que a Administração antecipe a habilitação, para verificar, junto aos particulares, quais deles possuem a qualificação técnica para alcançar o desiderato administrativo.

Nessa fase inicial do processo administrativo aquisitivo, a Administração poderá valer-se do instrumento de pré-qualificação, que funcionará como procedimento apto a verificar a qualificação técnica dos interessados em contratar com a Administração, tudo de acordo com previsão legal disposta no artigo 114 da Lei n 8.666/1993 (BRASIL, 1993),

humanos nas áreas de ciência, pesquisa, tecnologia e inovação, inclusive por meio do apoio às atividades de extensão tecnológica, e concederá aos que delas se ocupem meios e condições especiais de trabalho. $\S 4^{\circ} \mathrm{A}$ lei apoiará e estimulará as empresas que invistam em pesquisa, criação de tecnologia adequada ao País, formação e aperfeiçoamento de seus recursos humanos e que pratiquem sistemas de remuneração que assegurem ao empregado, desvinculada do salário, participação nos ganhos econômicos resultantes da produtividade de seu trabalho. $\S 5^{\circ}$ É facultado aos Estados e ao Distrito Federal vincular parcela de sua receita orçamentária a entidades públicas de fomento ao ensino e à pesquisa científica e tecnológica. § $6^{\circ} \mathrm{O}$ Estado, na execução das atividades previstas no caput, estimulará a articulação entre entes, tanto públicos quanto privados, nas diversas esferas de governo. $\S 7^{\circ} \mathrm{O}$ Estado promoverá e incentivará a atuação no exterior das instituições públicas de ciência, tecnologia e inovação, com vistas à execução das atividades previstas no caput.

Art. 219. O mercado interno integra o patrimônio nacional e será incentivado de modo a viabilizar o desenvolvimento cultural e sócio-econômico, o bem-estar da população e a autonomia tecnológica do País, nos termos de lei federal. Parágrafo único. O Estado estimulará a formação e o fortalecimento da inovação nas empresas, bem como nos demais entes, públicos ou privados, a constituição e a manutenção de parques e polos tecnológicos e de demais ambientes promotores da inovação, a atuação dos inventores independentes e a criação, absorção, difusão e transferência de tecnologia.

Art. 219-A. A União, os Estados, o Distrito Federal e os Municípios poderão firmar instrumentos de cooperação com órgãos e entidades públicos e com entidades privadas, inclusive para o compartilhamento de recursos humanos especializados e capacidade instalada, para a execução de projetos de pesquisa, de desenvolvimento científico e tecnológico e de inovação, mediante contrapartida financeira ou não financeira assumida pelo ente beneficiário, na forma da lei.

Art. 219-B. O Sistema Nacional de Ciência, Tecnologia e Inovação (SNCTI) será organizado em regime de colaboração entre entes, tanto públicos quanto privados, com vistas a promover o desenvolvimento científico e tecnológico e a inovação. § $1^{\circ}$ Lei federal disporá sobre as normas gerais do SNCTI. § $2^{\circ}$ Os Estados, o Distrito Federal e os Municípios legislarão concorrentemente sobre suas peculiaridades. 
verbis:

Art. 114. O sistema instituído nesta Lei não impede a pré-qualificação de licitantes nas concorrências, a ser procedida sempre que o objeto da licitação recomende análise mais detida da qualificação técnica dos interessados.

$\S 1^{\circ}$. A adoção do procedimento de pré-qualificação será feita mediante proposta da autoridade competente, aprovada pela imediatamente superior;

$\S 2^{\circ}$. Na pré-qualificação serão observadas as exigências desta Lei relativas à concorrência, à convocação dos interessados, ao procedimento e à análise da documentação.

De acordo com orientação do TCU (2008), a pré-qualificação consiste na antecipação da fase habilitatória da licitação, possível quando o objeto apresente peculiaridades que a justifique. O objeto deverá ser definido, dessarte, de maneira clara e precisa, indicando seus aspectos qualitativos e quantitativos:

Isto porque para que sejam selecionados licitantes aptos a executarem satisfatoriamente o objeto, tanto os participantes da pré-qualificação como das demais fases do procedimento licitatório devem estar cientes de todas as peculiaridades do objeto. Ademais, para que a Administração Pública decida pela pré-qualificação, deverá analisar todos os aspectos do objeto que se quer contratar a fim de verificar suas particularidades, para justificar, assim, a necessidade de realizar previamente a habilitação dos licitantes. (BRASIL. Tribunal de Contas da União. Acórdão $n^{\circ} 477 / 2008$ )

Segundo JUSTEN FILHO (2010, p. 950), a pré-qualificação é cabível apenas nas concorrências em que se exija uma qualificação técnica especial e superior à necessária a atividades normais. $\mathrm{O}$ autor leciona que a pré-qualificação envolve apreciação discricionária da Administração, e não será admissível quando a licitação não versar sobre objeto que apresente peculiaridades. Os requisitos estipulados - de acordo com os critérios usuais de necessidade e adequação - deverão ser compatíveis e indispensáveis à boa execução do contrato futuro.

Sobre o assunto, oportuno pontuar que o Tribunal de Contas da União (2008) aponta a necessidade de que a contratante se abstenha de estabelecer critérios classificatórios que utilizem como parâmetro de eliminação do certame a pontuação dos primeiros colocados, assim como previsão de limitação a um determinado número de qualificados previamente definido, por contrariarem os princípios da competitividade e isonomia. A Administração deverá limitar-se a estabelecer requisitos técnicos, jurídicos, financeiros e econômicos indispensáveis à garantia do cumprimento das obrigações a serem contratadas, com a estipulação de um mínimo de capacitação a ser atingido, nos termos do inciso XXI do artigo 
37 da Constituição Federal (BRASIL, 1988).

Para JACOBY FERNANDES (2016, p. 1048), a pré-qualificação tem a vantagem de antecipar a fase mais complexa da licitação, que é a habilitação, na qual são frequentes os recursos e ações judiciais. Além disso, a pré-qualificação independe da existência de recursos orçamentários, porque não gera o compromisso da contratação, no que se assemelha ao Sistema de Registro de Preços (SRP).

O autor levanta a importante discussão acerca da obrigatoriedade da licitação subsequente à pré-qualificação ser necessariamente concorrência, uma vez que o artigo 114 da Lei ${ }^{\circ}$ 8.666/1993 (BRASIL, 1993) poderia levar a esse entendimento. Porém, esclarece que, de acordo com sua visão, a lei permite estender o rigor da concorrência às outras modalidades, não havendo impedimento a usar-se a pré-qualificação para convite, tomada de preços, pregão, etc.

Nos contratos de pesquisa e desenvolvimento de novos produtos e novas tecnologias, a pré-qualificação pode ser muito útil funcionando também para selecionar o objeto da licitação, na qual se pode lançar um edital semelhante ao da concorrência, exigindo que os licitantes apresentem objeto (amostra) para ser avaliado e selecionado pela Administração, segundo critérios bem delineados no ato convocatório (JACOBY FERNANDES, 2016, p. 1050). O autor cita como exemplo a compra de portas de segurança para agências de um banco público, que utilizou esse sistema de pré-qualificação da seguinte forma: convocação pública (realizada através de pré-qualificação, na forma do art. 114 da Lei n 8.666/1993, seguindo os postulados de concorrência internacional) para que os interessados oferecessem amostra do produto; seguida de exame das amostras dos fornecedores possíveis, segundo os critérios técnicos já definidos e, por fim, licitação entre as empresas que ofereceram amostras julgadas satisfatórias. As aquisições, segundo afirma, foram realizadas na modalidade correspondente ao volume da aquisição pretendida, havendo compras que foram realizadas na modalidade convite, sendo admitidos apenas os fornecedores com os objetos pré-qualificados. Todo o procedimento foi julgado regular pelo Tribunal de Contas da União (BRASIL, 1995).

Isto posto, verifica-se que a pré-qualificação - muito embora não seja exclusiva para as hipóteses de contratação de pesquisa e desenvolvimento estando prevista, inclusive no regime diferenciado de contratações públicas (RDC), Lei n ${ }^{\circ} 12.462 / 11$, art. 29 e seguintes poderá ser muito útil na escolha de participantes hábeis a desempenhar o objeto contratual intentado pela administração, de acordo com suas particularidades. 


\section{A MUTABILIDADE DO PROJETO BÁSICO}

É frequente, em contratações versando sobre projetos de pesquisa e desenvolvimento, que o projeto básico ${ }^{2}$ necessite ser alterado após a assinatura do contrato, em consequência de inovações alcançadas ou mesmo de novas descobertas científicas realizadas durante a execução contratual, decorrentes do advento de novas circunstâncias fáticas e/ou descobertas tecnológicas. O projeto de construção de um equipamento de exploração subaquática, por exemplo, pode ser alterado diante de dificuldades não previstas advindas de adversidades geológicas do local onde o equipamento será utilizado. Em decorrência desse fato, a autoria técnica do projeto deverá manejar novas potencialidades para o equipamento que cumprirá a mesma função prevista no contrato originalmente celebrado, porém o projeto inicial será alterado, muito embora o escopo contratual permanecerá o mesmo.

Em termos legislativos, a Lei $n^{\circ} 8.666$ (BRASIL, 1993) prevê a possibilidade de alteração contratual unilateral pela Administração, quando houver modificação do projeto ou das especificações, para melhor adequação técnica aos seus objetivos, desde que presentes as devidas justificativas (art. 65, I, a).

Nesse particular, a jurisprudência do Tribunal de Contas da União (BRASIL, 2006) indica a necessidade de fazer constar do processo de contratação a devida justificativa para a alteração do contrato, com projeto ou especificações que detalhem, de forma clara, o objeto a ser modificado ou acrescido, bem como as respectivas quantidades, de modo a possibilitar a correta cotação de preços, nos termos do que dispõe o art. $7^{\circ}, \S 4^{\circ}$ da Lei $n^{\circ} 8.666 / 1993$. Essa justificativa técnica deverá constar dos autos do procedimento licitatório (BRASIL, TCU, NARDES, 2006).

Importante esclarecer, entretanto, que a alteração do projeto não poderá implicar em projeto totalmente distinto do original, devendo guardar semelhança com o anterior. Do contrário, a alteração deverá reclamar nova licitação (BRASIL, TCU, 1997).

Para JUSTEN FILHO (2010, p. 771), é importante que a Administração evidencie a superveniência do motivo justificador da alteração contratual, devendo demonstrar que a solução localizada na fase interna da licitação não mais se revelou adequada em um momento

$2 \mathrm{O}$ artigo $6^{\circ}$, inciso IX da Lei $\mathrm{n}^{\circ} 8.666 / 93$ define projeto básico como "conjunto de elementos necessários e suficientes, com nível de precisão adequado, para caracterizar a obra ou serviço, ou complexo de obras ou serviços objeto da licitação, elaborado com base nas indicações dos estudos técnicos preliminares, que assegurem a viabilidade técnica e o adequado tratamento do impacto ambiental do empreendimento, e que possibilite a avaliação do custo da obra e a definição dos métodos e do prazo de execução". (BRASIL, 1993) 
posterior. Deverá, portanto, indicar quais fatores alteraram a situação de fato ou de direito e reclamam um tratamento distinto daquele adotado. Conforme assinala, "a melhor adequação técnica supõe a descoberta ou a revelação de circunstâncias desconhecidas acerca da execução da prestação ou a constatação de que a solução técnica anteriormente adotada não era a mais adequada".

Além disso, o autor admite alterações desse tipo na hipótese de modificações derivadas de situações preexistentes, mas desconhecidas por parte dos interessados, chamadas pela doutrina francesa de "sujeições imprevistas", que seriam eventos da natureza ou fora do controle dos seres humanos, existentes por ocasião da contratação, mas cuja revelação se verifica apenas por ocasião da execução da prestação.

Também ocorrem tais alterações nas inovações tecnológicas que apresentem soluções de qualidade superior àquela da época da contratação (o que é frequente nas contratações de tecnologia da informação). Em tais casos, assevera, é dever da administração promover alterações para assegurar a obtenção de objetos adequados e satisfatórios, "evitando o recebimento de prestação obsoleta”. Conclui que os contratos de longo prazo ou de grande especialização - como é o caso de contratações cujo objeto é a pesquisa e o desenvolvimento - são mais suscetíveis a essa modalidade de alteração e que não há cabimento para essa hipótese de alteração nos contratos de execução instantânea.

\section{EVENTUAL ANTECIPAÇÃO DE PAGAMENTO}

Muitas vezes, em contratos em matéria de pesquisa e desenvolvimento de produtos de alta complexidade tecnológica, o particular contratado pode não deter, de início, todo o capital necessário para investir em equipamentos de grande porte ou contratar pessoal altamente especializado que o possibilitará executar o contrato. A Administração, por outro lado, já deverá possuir a dotação orçamentária e os recursos alocados para o pagamento do contrato, não podendo ser realocados.

Em tais casos, a conveniência da antecipação de pagamento é evidente, conforme afirma JUSTEN FILHO (2010, p. 716). A Administração, objetivando que os recursos não fiquem sem aplicação até o término do escopo do contrato, poderá efetivar o pagamento antecipado para que não haja a desvalorização da moeda, bem como para evitar o pagamento de reajustes contratuais ou recomposições extraordinárias de preços.

$\mathrm{O}$ autor cita ainda casos nos quais a antecipação de pagamento seria obrigatória: 
quando a execução do contrato exige investimentos de grande porte, de maneira que esta se torna condição de ampliação do universo de participantes. De acordo com seu raciocínio, quando se proíbe o pagamento antecipado e se institui a prévia execução do serviço ou entrega do bem, impõe-se a restrição à participação no processo licitatório, que seria ainda mais reprovável por ser indireta e oculta.

O Tribunal de Contas da União (BRASIL, 1998) já decidiu a regularidade do pagamento antecipado para acelerar o ritmo de execução de obras, à vista de sua regular conclusão, uma vez que a antecipação deveu-se à ordem para comprar material, após a colocação no canteiro.

Seja qual for a hipótese ensejadora da excepcionalidade da antecipação, o pagamento antecipado não poderá representar benesse injustificada para o contratado. A regra geral é a de que o pagamento se faça após comprovada a execução da prestação a cargo do particular.

A previsão legal da antecipação do pagamento na lei de licitações consta do artigo 40, XIV, alínea 'd' (BRASIL, 1993). Nesse dispositivo, a lei autorizou previsão no edital de cláusula acerca de antecipação de pagamento. Demais disso, o artigo 38 do Decreto ${ }^{\circ}$ 93.872/1986 (BRASIL, 1986) autoriza a antecipação de pagamento de parcela contratual, em caráter excepcional, desde que apresentadas as indispensáveis cautelas e garantias.

Na leitura de JUSTEN FILHO (2010, p. 716), a jurisprudência do TCU aponta para a necessidade da presença de dois requisitos principais para a regularidade do pagamento antecipado: a previsão no ato convocatório e a prestação de garantias efetivas e idôneas destinadas a evitar prejuízos à Administração.

Há, entretanto, um posicionamento contrário à possibilidade de antecipação de pagamento, de acordo com entendimento do TCU (ROCHA, 1999). Segundo os defensores dessa corrente, o art. 62 da Lei $n^{\circ} 4.320$ (BRASIL, 1964), quando ordenou o pagamento de despesa somente após sua liquidação, vetou a realização do pagamento antecipado. Outro argumento seria a vedação presidencial do pagamento antecipado, prevista no projeto de lei da atual lei de licitações, art. $55 \S^{\circ}$ da Lei n ${ }^{\circ}$ 8.666/1993 (BRASIL, 1993).

Todavia, para MEIRELLES (1990), é possível a antecipação, desde que a Administração exija, por cautela, fiança bancária até o recebimento do objeto do contrato.

Este entendimento parece coadunar com o posicionamento da Advocacia-Geral da União, exarado na Orientação Normativa n 37/2011 (Portaria AGU n 572/2011), na qual se lê:

A antecipação de pagamento somente deve ser admitida em situações excepcionais, devidamente justificada pela Administração, demonstrando-se a existência de interesse 
público, observados os seguintes critérios: 1) represente condição sem a qual não seja possível obter o bem ou assegurar a prestação do serviço, ou propicie sensível economia de recursos; 2) existência de previsão no edital de licitação ou nos instrumentos formais de contratação direta; e 3) adoção de indispensáveis garantias, como as do art. 56 da lei $\mathrm{n}^{\circ}$ 8.666/93, ou cautelas, como por exemplo a previsão de devolução do valor antecipado caso não executado o objeto, a comprovação de execução de parte ou etapa do objeto e a emissão de título de crédito pelo contratado, entre outras

$\mathrm{Na}$ fundamentação do entendimento sumular, faz-se referência, em síntese, aos requisitos necessários à antecipação de pagamento: excepcionalidade da situação; justificativa do interesse público; represente condição indispensável à obtenção do bem/serviço ou economia de recursos; apresentação de garantias ou cautelas.

Sendo assim, a antecipação do pagamento é uma possibilidade que pode auxiliar as contratações de projetos de grande complexidade tecnológica e inovação, com pesquisa e desenvolvimento de novos produtos/serviços, por viabilizar a contratação para os contratados que não possuem recursos para dar o pontapé inicial no processo produtivo, bem como possivelmente representar economia de recursos por parte da Administração Pública, que fará o desembolso antecipadamente.

Além de ampliar a competitividade - objetivo perseguido nas licitações públicas - o fato de permitir que empresas pertencentes à Base Industrial de Defesa, por exemplo, possam concorrer em certames licitatórios baseados em projetos de pesquisa, desenvolvimento e inovação que permitam uma antecipação de pagamento que viabilize o início do andamento do projeto, coaduna-se com um eixo estruturante da Estratégia Nacional de Defesa descrita no Decreto $n^{\circ} 6.703 / 08$ (BRASIL, 2008). ${ }^{3}$

\section{ENQUADRAMENTO COMO CONTRATAÇÃO POR ESCOPO}

Durante o desenrolar do chamado "ciclo de vida dos materiais", os contratos de pesquisa e desenvolvimento da Administração Pública são aqueles comumente celebrados na primeira fase da jornada de criação de produtos, podendo ter por objeto protótipos, lotes cabeça de série, lotes piloto, etc.

Como já dito acima, a pesquisa e desenvolvimento de produto que inova no estado atual da técnica requer olhar diferenciado sobre a contratação, diante das especificidades da contratação. Uma delas relaciona-se ao fato de que o contrato de pesquisa e desenvolvimento

3 A Estratégia Nacional de Defesa organiza-se em torno de três eixos estruturantes. O segundo eixo estruturante refere-se à reorganização da indústria nacional de material de defesa, para assegurar que o atendimento das necessidades de equipamento das Forças Armadas apoie-se em tecnologias sob domínio nacional. 
pode ou não gerar um resultado eficaz após todo o desenrolar da execução contratual, uma vez que o produto pode não atingir o desiderato almejado pela Administração. Isto é, o produto entregue após a conclusão de um projeto de PD\&I, pode carecer de estudos posteriores e avançados que permitam seu pleno desenvolvimento para os fins a que se destina. Essa característica se mostra destacada quando se trata de Produto de Defesa com finalidade de emprego no âmbito das Forças Armadas do País, vez que tais materiais necessitam de exaustiva fase de testes e avaliações para que possam ser empregados em atividades finalísticas militares.

Outras vezes, o contrato pode sofrer aditivos sucessivos para que os prazos anteriormente contratados sejam estendidos de forma a permitir a conclusão dos trabalhos de pesquisa relacionados com a conclusão do projeto em desenvolvimento.

Sendo assim, a questão da imprevisibilidade do sucesso da inovação possui repercussões no campo da duração contratual, uma vez que é impossível precisar, principalmente no âmbito da contratação de protótipo, por quanto tempo durará o rpojeto - até que se alcancem o resultado ou inovação tecnológica pretendida - ou, até mesmo, se tal contratação será efetivamente exitosa, produzindo a eficácia esperada pela Administração.

A correta caracterização da espécie contratual, no que se refere aos contratos sob enfoque nesse artigo, produz reflexos relativamente ao prazo de vigência, o qual desempenha função normativa diversa em cada caso (JUSTEN FILHO, 2010, p. 723). Nos contratos por escopo (ou de execução instantânea), o prazo de vigência é fixado em face do tempo necessário e adequado para a execução do objeto, ao passo que nos contratos de execução continuada, o prazo de vigência destina-se a estabelecer o período de tempo durante o qual a contratação produzirá efeitos, uma vez que nesta espécie contratual existe uma clara dissociação entre as condições temporais para a execução da prestação e o prazo de vigência. Nos serviços contínuos, o prazo é determinado de acordo com as necessidades públicas permanentes (Lei n ${ }^{\circ} 8.666 / 1993$, art. 57, II).

Por esta razão, muito embora essas contratações em matéria de pesquisa e desenvolvimento de produtos tecnológicos se aproximem da definição de serviços continuados, a sua real natureza jurídica enquadra-se no conceito de contratações por escopo, como informam recentes posicionamentos da Advocacia-Geral da União (BRASIL, 2017; BRASIL, 2016), muito embora o desenrolar da execução contratual envolva a continuidade do trabalho intelectual/fabril de equipes técnicas que configuram, faticamente, uma prestação de serviços. 
Nos contratos por escopo, a sua extinção normal se dá com a conclusão de seu objeto, de maneira que a fixação do prazo será relevante para que a Administração exija do particular executante um mínimo de eficiência e celeridade necessárias para a satisfação do interesse público. Nesses casos, o prazo de vigência será aquele necessário para que a parte promova a prestação devida.

Ainda sobre a diferenciação entre os contratos por escopo, dos contratos de execução continuada, SUNDFELD (1994, p. 222), ressalta que, no contrato por escopo, a Administração pretende a entrega de um objeto certo e acabado:

\begin{abstract}
"A administração contrata a obtenção de um bem determinado e o escopo do contrato estará consumado quando entregue esse bem, ou seja, quando cumprido o objeto do contrato na entrega da obra, serviço ou da compra. Neste tipo de contrato, pela sua natureza, ocorrerá sua extinção normal com a conclusão de seu objeto, ou seja, realizando a conduta específica e definida no objeto do contrato. Assim sendo, o mais importante é a conclusão da prestação de serviço por parte da contratada."
\end{abstract}

Isto posto, a correta caracterização dos contratos sob análise como contratos de escopo (ou de execução instantânea) faz-se necessária para reflexões sobre sua duração, assim como, sobre sua vigência.

\title{
6. SÓLIDO GERENCIAMENTO DE RISCOS
}

Progressivamente, nos últimos anos, o direito administrativo vem incorporando um conceito do ramo empresarial que, aliado aos tradicionais princípios da Administração, se coloca como instrumento auxiliar do planejamento das contratações públicas. Trata-se da gestão de riscos.

A nova lei das estatais, Lei ${ }^{\circ}$ 13.303/16 (BRASIL, 2016), por exemplo, traz em seu bojo variadas menções à gestão de riscos, sob diversos enfoques ${ }^{4}$. Especificamente no que toca às contratações realizadas pelas empresas estatais, o mencionado diploma legal impõe a imprescindibilidade da presença da matriz de riscos ${ }^{5}$ no instrumento convocatório (art. 42, §

4 A gestão de riscos aparece na Lei ${ }^{\circ}$ 13.303/16 como princípio de imperiosa observância na elaboração dos estatutos das empresas públicas e das sociedades de economia mista (art. $\left.6^{\circ}\right)$. Outras práticas relacionadas à conscientização dos riscos na gestão estão impostas na lei como divulgação de fatores de risco como requisito de transparência (art. $8^{\circ}$, III); imposição de práticas de gestão de risco por parte de administradores e empregados (art. $9^{\circ}$ caput e inciso II); necessidade de treinamento periódico de empregados e administradores em política da gestão de riscos (art. $9^{\circ}, \S 1^{\circ}, \mathrm{VI}$ ); a implementação e supervisão dos sistemas de gestão de riscos como uma das competências do Conselho de Administração (art. 18, II), dentre outras.

$5 \mathrm{O}$ artigo 42, $\mathrm{X}$ da Lei $\mathrm{n}^{\circ}$ 13.303/16 define matriz de riscos como “cláusula contratual definidora de riscos e responsabilidades entre as partes e caracterizadora do equilíbrio econômico-financeiro inicial do contrato, 
$1^{\circ}$, I, alínea 'd' assim como na cláusula dos contratos celebrados de acordo com aquela lei (art. 69, X).

Desta forma, a gestão de riscos configura novo elemento do planejamento das contratações que vem sendo altamente valorado pelo legislador e pelos órgãos de controle administrativo como o Tribunal de Contas da União, como figura indispensável à contratação. Mas, o que vem a ser gerenciamento de riscos?

A recente e moderna Instrução Normativa ${ }^{\circ}$ 05, de 25 de maio de $2017^{6}$ (BRASIL, 2017) - diploma normativo que dispõe sobre as regras e diretrizes do procedimento de contratação de serviços sob o regime de execução indireta no âmbito da Administração Pública Federal direta, autárquica e fundacional - disciplina o gerenciamento de riscos como um processo, o qual compreende algumas atividades tais como:

"I - identificação dos principais riscos que possam comprometer a efetividade do Planejamento da Contratação, da Seleção do Fornecedor e da Gestão Contratual ou que impeçam o alcance dos resultados que atendam às necessidades da contratação;

em termos de ônus financeiro decorrente de eventos supervenientes à contratação, contendo, no mínimo, as seguintes informações: a) listagem de possíveis eventos supervenientes à assinatura do contrato, impactantes no equilíbrio econômico-financeiro da avença, e previsão de eventual necessidade de prolação de termo aditivo quando de sua ocorrência; $b$ ) estabelecimento preciso das frações do objeto em que haverá liberdade das contratadas para inovar em soluções metodológicas ou tecnológicas, em obrigações de resultado, em termos de modificação das soluções previamente delineadas no anteprojeto ou no projeto básico da licitação; c) estabelecimento preciso das frações do objeto em que não haverá liberdade das contratadas para inovar em soluções metodológicas ou tecnológicas, em obrigações de meio, devendo haver obrigação de identidade entre a execução e a solução pré-definida no anteprojeto ou no projeto básico da licitação."

6 Editada pelo Ministério do Planejamento, Desenvolvimento e Gestão, a Instrução Normativa ${ }^{\circ} 05$, de 25 de Maio de 2017, veio a substituir a Instrução Normativa $n^{\circ} 2$, de 30 de abril de 2008. Os motivos ensejadores da revisão do anterior diploma legal são os seguintes: “Desde a sua edição, a IN $n^{o} 2$, de 2008, vem sofrendo alterações em razão das inúmeras modificações na legislação que trata de licitações públicas, bem como das mudanças de interpretação de seus dispositivos. Em razão disso, sua redação não se encontrava com a melhor qualidade textual, motivo pelo qual buscou-se equacionar seus dispositivos com a utilização de técnica legislativa adequada que garanta maior coerência, compreensão e aplicabilidade. Além dessa reformulação, o Tribunal de Contas da União editou o Acórdão $n^{o}$ 2.622/2015-TCU - Plenário que objetivou sistematizar informações sobre o estágio da governança e da gestão das aquisições em amostra da Administração Pública Federal (APF). Esse Acórdão propôs várias medidas visando ao aperfeiçoamento da governança e da gestão das contratações realizadas pela Administração Pública Federal, merecendo destaque a constatação quanto à existência de disfunções existentes na atual metodologia para contratação de serviços, em especial dos que envolvem a contratação de serviços sob o regime de dedicação exclusiva. Outro fato importante foi a edição da Portaria $n^{\circ} 409$, de 21 de dezembro de 2016, que dispõe sobre as garantias contratuais a trabalhador na execução indireta de serviços e os limites à terceirização de atividades, no âmbito da Administração Pública federal direta, autárquica e fundacional e das empresas estatais federais controladas pela União. A nova IN também objetivou adequar-se às disposições dessa Portaria que regulamenta o art. $9^{\circ}$ do Decreto $n^{o} 2.271,1997$, em atenção aos Acórdãos $n^{o}$ s. 243/2002, 2.132/2010, 2.303/2012 e 1.521/2016 - TCU - Plenário, bem como procedimentalizar e sistematizar, de maneira geral, matérias que foram objeto de alterações jurisprudenciais e doutrinárias, indo ao encontro do que dispõe a Súmula 331 do TST, ou seja, implementa regras garantidoras do cumprimento da legislação trabalhista e mitigadoras de inadimplência por parte da prestadora de serviços." Disponível em: < https://www.comprasgovernamentais.gov.br/index.php/in-servico-faq\#P1>. Acesso em 01 de mar. 2018. 
II - avaliação dos riscos identificados, consistindo na mensuração da probabilidade de ocorrência e do impacto de cada risco;

III - tratamento dos riscos considerados inaceitáveis por meio da definição das ações para reduzir a probabilidade de ocorrência dos eventos ou suas consequências;

IV - para os riscos que persistirem inaceitáveis após o tratamento, definição das ações de contingência para o caso de os eventos correspondentes aos riscos se concretizarem; e

$\mathrm{V}$ - definição dos responsáveis pelas ações de tratamento dos riscos e das ações de contingência."

O mesmo diploma legal atribui a responsabilidade pelo gerenciamento de riscos à equipe de planejamento da contratação, devendo abranger as fases do procedimento da contratação. Coloca, portanto, sobre tal equipe, a incumbência de elaboração do Mapa de Riscos, documento que, segundo a instrução normativa, materializa o gerenciamento de riscos (art. 26).

Assim como a instrução normativa sobre serviços indiretos da Administração Federal, o projeto de lei que pretende alterar a lei de licitações, PL 6.814/17 (BRASIL, 2017), traz em seu bojo diversas imposições ao administrador no sentido de mensuração dos riscos quando do planejamento da contratação e da contratação propriamente dita.

Sendo assim, pode-se dizer que, diante dos diplomas legais vigentes, a análise dos riscos é uma realidade das contratações públicas atuais (CASTRO, 2016), assim como, de outra parte, o incremento do risco de dano ao erário configura fator de avaliação dos órgãos de controle externo, uma vez que são um indicativo da cautela (ou ausência de cautela) na conduta do administrador.

Com muito mais razão, nas contratações versando sobre inovações tecnológicas, é importante que os agentes da administração responsáveis pela identificação, avaliação e tratamento dos riscos identificados, busquem mensurar as reais chances de sucesso nas soluções buscadas pelas contratações celebradas.

Em se tratando de contratações que podem ou não ser exitosas no desenvolvimento de bem inexistente no atual estado da técnica, os riscos que impeçam o alcance dos resultados que atendam às necessidades da contratação podem, a guiza de princípio, ser mais fortes. Por esta razão, quando do planejamento da contratação, estes riscos devem ser solidamente mapeados, para pautar boas escolhas por parte do administrador que, seguramente, sofrerá avaliação por parte dos órgãos de controle da administração, tanto internos quanto externos.

\section{CONCLUSÃO}

Diante das características levantadas, procurou-se abordar o espinhoso tema das 
contratações de inovação e desenvolvimento tecnológico por parte da Administração Federal. Além das particularidades abordadas - possibilidade de adoção de procedimento de préqualificação, mutabilidade do projeto básico, eventual antecipação de pagamento, enquadramento como contrato de escopo, sólido gerenciamento de riscos - diversas outras poderiam ter sido apontadas, o que ultrapassaria o objetivo do presente trabalho, que não é esgotar o tema acerca das especifidades de tais contratações, mas apenas jogar uma luz nas suas particularidades.

Procurou-se trazer esta espécie contratual para estudo e problematização, por ser, modernamente, uma modalidade contratual em voga nas contratações da administração, em particular nos órgãos estatais incumbidos da realização de pesquisa, desenvolvimento e inovação nas áreas afetas à Ciência e Tecnologia, muito embora ainda não seja tratada pelos manuais de direito administrativo a miúde, uma vez que situam-se na interseção entre o campo do direito administrativo, na área de licitações e contratos e campo do direito empresarial na parte de inovação e direitos da propriedade intelectual.

Isto posto, conclui-se deixando o tema aberto para reflexão e aprofundamento doutrinário, em razão de sua importância prática e teórica.

\section{REFERÊNCIAS}

BRASIL. Advocacia Geral da União. Portaria ${ }^{\circ}$ 572, de 13 de dezembro de 2011. Edita as Orientações Normativas $n^{\circ} 33,34,35,36,37,38$ e 39, e altera as Orientações Normativas $n^{\circ}$ s 10, 17, 21, 23, 24, 25 e 26. Diário Oficial da União, Brasília, DF, 14 dez. 2011.

BRASIL. Advocacia Geral da União. I - Termo aditivo II - Possibilidade com ressalvas. Parecer $n^{\circ}$ 03789/2017/CJU-RJ/CGU/AGU, de 18 de outubro de 2017. Relator: Luiz Carlos Pereira Baia. Disponível em: <https://sapiens.agu.gov.br/documento/83045943>, acesso em 12 de março de 2018.

BRASIL. Advocacia Geral da União. Termos aditivos de vigência/acréscimo/supressão contratual; solicitação para prorrogação da vigência do contrato de desenvolvimento do míssil tático de cruzeiros Astros AV-TM 300; possibilidade prosseguimento, com ressalvas. Parecer $\mathrm{n}^{\circ}$ 01317/2016/CJU-RJ/CGU/AGU, de 28 de abril de 2016. Relator: Nelson Orlando de Alarcão Duccini. Disponível em: 〈https://sapiens.agu.gov.br〉, acesso em 15 de março de 2018.

BRASIL. Câmara dos Deputados. Projeto de Lei $\mathrm{n}^{\circ}$ 6.814/2017. Disponível em: <http://www.camara.gov.br/proposicoesWeb/fichadetramitacao?idProposicao=2122766 >. Acesso em: 01 abr. 2018.

BRASIL. Constituição Federal de 1988. Diário Oficial da União, Brasília, DF, 5 out. 1988. 
Disponível em: <http://www.planalto.gov.br/ccivil 03/constituicao/constituicao.htm>. Acesso em: 05 abr. 2018.

BRASIL. Decreto $\mathrm{n}^{\circ}$ 93.872, de 23 de dezembro de 1986. Dispõe sobre a unificação dos recursos de caixa do Tesouro Nacional, atualiza e consolida a legislação pertinente e dá outras providências. Diário Oficial da União, Brasília, DF, 24 dez. 1986. Disponível em: <http://www.planalto.gov.br/ccivil_03/decreto/d93872.htm>. Acesso em: 10 abr. 2017.

BRASIL. Decreto $n^{\circ}$ 6.703, de 18 de dezembro de 2008. Aprova a Estratégia Nacional de Defesa, e dá outras providências. Diário Oficial da União, Brasília, DF, 19 dez. 2008. Disponível em: <http://www.planalto.gov.br/ccivil_03/_ato20072010/2008/decreto/d6703.htm>. Acesso em: 08 abr. 2018.

BRASIL. Lei $\mathrm{n}^{\circ}$ 13.303, de 30 de junho de 2016. Dispõe sobre o estatuto jurídico da empresa pública, da sociedade de economia mista e de suas subsidiárias, no âmbito da União, dos Estados, do Distrito Federal e dos Municípios. Diário Oficial da União, Brasília, DF, 01 jul. 2016. Disponível em: <http://www.planalto.gov.br/ccivil_03/_ato20152018/2016/lei/113303.htm>. Acesso em: 10 abr. 2018.

BRASIL. Lei $\mathrm{n}^{\mathrm{o}}$ 8.666, de 21 de junho de 1993. Regulamenta o art. 37, inciso XXI, da Constituição Federal, institui normas para licitações e contratos da Administração Pública e dá outras providências. Diário Oficial da União, Brasília, DF, 22 jun. 1993. Disponível em: <http://www.planalto.gov.br/ccivil_03/Leis/L8666cons.htm>. Acesso em: 10 abr. 2017.

BRASIL. Ministério do Planejamento, Desenvolvimento e Gestão. Instrução Normativa $\mathrm{n}^{\circ}$ 05, de 25 de maio de 2017. Dispõe sobre as regras e diretrizes do procedimento de contratação de serviços sob o regime de execução indireta no âmbito da Administração Pública federal direta, autárquica e fundacional. Diário Oficial da União, Brasília, DF, 26 mai. 2017.2 Disponível em: $<$ https://www.comprasgovernamentais.gov.br/index.php/legislacao/instrucoesnormativas/760-instrucao-normativa-n-05-de-25-de-maio-de-2017> . Acesso em 04 jun. 2017.

BRASIL. Tribunal de Contas da União. Decisão n 491/1995. Plenário. Relator: Ministro Iram Saraiva. Sessão de 20/09/1995. Diário Oficial da União, Brasília, DF, 20 set. 1995.

BRASIL. Tribunal de Contas da União. Decisão $n^{\circ}$ 63/1997. Plenário. Relator: Ministro Lincoln Magalhães da Rocha. Sessão de 19/02/1997. Diário Oficial da União, Brasília, DF, 19 fev. 1997.

BRASIL. Tribunal de Contas da União. Decisão no 110/1998. Primeira Câmara. Relator: Ministro Iram Saraiva. Sessão de 14/04/1998. Diário Oficial da União, Brasília, DF, 14 abr. 1998.

BRASIL. Tribunal de Contas da União. Acórdão n 237/1999. Plenário. Relator: Ministro Lincoln Magalhães da Rocha. Sessão de 15/12/1999. Diário Oficial da União, Brasília, DF, 15 dez. 1999.

BRASIL. Tribunal de Contas da União. Acórdão n 866/2006. Plenário. Relator: Ministro Augusto Nardes. Sessão de 07/06/2006. Diário Oficial da União, Brasília, DF, 07 jun. 2006. 
BRASIL. Tribunal de Contas da União. Acórdão n 1730/2006. Plenário. Relator: Ministro Valmir Campelo. Sessão de 20/09/2006. Diário Oficial da União, Brasília, DF, 20 set. 2006.

BRASIL. Tribunal de Contas da União. Acórdão n ${ }^{\circ}$ 477/2008. Plenário. Relator: Ministro Benjamin Zymler. Sessão de 26/03/2008. Diário Oficial da União, Brasília, DF, 26 mar. 2008.

CASTRO, Rodrigo Pironti Aguirre de. Matriz e Gestão de Riscos: uma nova realidade nas contratações públicas. Blog Zenite. Disponível em: <https://www.zenite.blog.br/matriz-egestao-de-riscos-uma-nova-realidade-nas-contratacoes-publicas/>. Acesso em: 04 mar. 2018.

JACOBY FERNANDES, Jorge Ulisses. Vade-mécum de licitações e contratos. Legislação: organização e seleção, jurisprudência, notas e índices de Jorge Ulisses Jacoby Fernandes. 7. ed. Belo Horizonte: Forum, 2016.

JUSTEN FILHO, Marçal. Comentários à lei de licitações e contratos administrativos. $14^{\mathrm{a}}$ ed. São Paulo: Dialética, 2010.

MAZZOCO, Carlos Fernando. Duração do contrato administrativo. Revista Jus Navigandi, ISSN 1518-4862, Teresina, ano 7, n. 59, 01 out. 2012. Disponível em: <https://jus.com.br/artigos/3255/duracao-do-contrato-administrativo/1> Acesso em: 15 mar. 2018.

MEIRELLES, Hely Lopes. Licitação e contrato administrativo. $14^{\mathrm{a}}$ ed. São Paulo: Malheiros, 2006.

SUNFELD, Carlos Ari. Licitação e Contrato Administrativo. São Paulo: Malheiros, 1994. 